\title{
Effect of Fenspiride on Bronchial Smooth Muscle of Rats with Chronic Obstructive Pulmonary Disease
}

\author{
Nataliya A. Kuzubova ${ }^{1}$, Elena S. Lebedeva ${ }^{1}$, Anatoliy N. Fedin ${ }^{2}$, Ivetta V. Dvorakovskaya ${ }^{1}$, \\ Tatiana N. Preobrazhenskaya ${ }^{1}$ and Olga N. Titova ${ }^{1}$ \\ ${ }^{1}$ Research Institute of Pulmonology, I. P. Pavlov's Saint-Petersburg State Medical University, \\ Russia \\ ${ }^{2}$ I. M. Sechenov's Institute of Evolutionary Physiology and Biochemistry, Russia
}

\begin{abstract}
Chronic obstructive pulmonary disease (COPD) is among the leading causes of morbidity and mortality worldwide. Glucocorticoids are currently the most applicable anti-inflammatory treatment for COPD. However, a subset of COPD subjects is relatively insensitive to this treatment. Fenspiride, a non-corticosteroid anti-inflammatory drug, has been described to have beneficial effects in patients with COPD, although the mechanism of its action is not well known. The effect of fenspiride on contractile activity of bronchial smooth muscle was studied in a rat model of COPD induced by long-term exposure of the animals to nitrogen dioxide $\left(\mathrm{NO}_{2}\right)$. Contractile activity of bronchial smooth muscle was evaluated in vitro. Isometric contraction of bronchial preparations was measured following electrical stimulation. Fenspiride administration to rats during the acute stage of COPD ( 15 days of $\mathrm{NO}_{2}$ exposure) prevented the bronchial constriction induced by $\mathrm{NO}_{2}$. The bronchodilator effect of a low-dose of fenspiride $(0.15 \mathrm{mg} / \mathrm{kg})$ was mediated by interaction with the nerve endings of capsaicin-sensitive C-fibers. Interaction of fenspiride with $\mathrm{C}$-fibers was shown to prevent initiation of neurogenic inflammation, as evidenced by lack of COPD-like structural changes in the lungs. The bronchodilator effect of a high-dose of fenspiride $(15 \mathrm{mg} / \mathrm{kg})$ was mediated not only by the afferent component, but also involved a direct relaxing effect on smooth muscle cells. The anti-inflammatory and bronchodilator effects of a low-dose of fenspiride may be used for prevention of COPD development in individuals from high-risk cohorts exposed to aggressive environmental factors.
\end{abstract}

Key words: fenspiride, chronic obstructive pulmonary disease, bronchial smooth muscle, rat

Corresponding author: Elena S. Lebedeva, PhD., Department of Experimental Pulmonology and Pathomorphology, Research Institute of Pulmonology, I. P. Pavlov's Saint-Petersburg State Medical University, Roentgen str., 12, Saint-Petersburg, 197022, Russia

Phone: +7 (812) 499-68-20 Fax: +7 (812) 234-90-46 e-mail: osmelena@mail.ru

C2013 The Japan Society of Smooth Muscle Research 


\section{Introduction}

Chronic obstructive pulmonary disease (COPD) is among the leading causes of morbidity and mortality worldwide. The primary pathophysiological mechanisms of chronic inflammation underlying COPD are associated with exposure to environmental pollutants and pathological changes involving all lung structures, i.e. bronchi, interstitial tissue, and alveoli. Current pharmacological therapies for COPD, mostly employing glucocorticosteroids, can not prevent progressive deterioration of respiratory function. The phenomenon of resistance of COPD patients to corticosteroid anti-inflammatory action is likely to be associated with reduced activity/expression of histone deacetylase 2 and the inhibition of inflammatory gene transcription as a consequence (1). Reduction of bronchial obstruction under the influence of corticosteroid treatment occurs in only $10-30 \%$ of COPD patients (2). Such a high rate of glucocorticosteroid resistance in COPD patients certainly mandates the search for novel drugs with bronchodilatory and anti-inflammatory effects for the treatment of COPD. Fenspiride, a non-corticosteroid anti-inflammatory drug, has been described to have beneficial effects in patients with COPD although the mechanism of its action is not well known $(2,3)$.

The aim of this study was to assess the dilatation effect of fenspiride upon bronchial smooth muscle in an experimental model of COPD induced by a prolonged exposure to nitrogen dioxide.

\section{Methods}

Experiments were performed in a total of fifty-two male juvenile Wistar rats weighing 150-170 g (Laboratory Animal Breeding "Rappolovo" of the Russian Academy of Sciences, St. Petersburg, Russia). All procedures and experiments were carried out in accordance with the internationally accepted guidelines for the care and use of laboratory animals (4). Rats were housed in cages $\left(250 \mathrm{~cm}^{2} / \mathrm{rat}\right)$ with free access to drinking water and standard lab rodent chow and maintained at $20-22^{\circ} \mathrm{C}$ and a humidity of $55-60 \%$.

An experimental model of COPD formation was based on nitrogen dioxide $\left(\mathrm{NO}_{2}\right)$ exposure $(5,6)$. Animals were placed in a chamber mounted under an exhaust hood and connected with a $\mathrm{NO}_{2}$-generator. A mixture of nitrogen oxides was produced in a chemical reaction between sodium nitrite and sulfuric acid and then pumped into the exposure chamber which was provided with an outlet tube. Colorless nitrogen oxide (NO) reacted with atmospheric oxygen and converted to the more stable yellow-brown $\mathrm{NO}_{2}$. The nitrogen dioxide concentration in the chamber was equal to $30-40 \mathrm{mg} / \mathrm{m}^{3}(15-19 \mathrm{ppm})$ as determined by a colorimetric method. Rats were exposed to $\mathrm{NO}_{2}$ using an intermittent regime of three 30-minute exposures separated by 30 min intervals each day for either 15 or 60 days. A group of 28 rats was treated with fenspiride (Erespal ${ }^{\circledR}$, Lab. Industry Servier, France). The drug was injected using an esophageal probe an hour prior to $\mathrm{NO}_{2}$ inhalation. Fourteen rats received $15 \mathrm{mg} / \mathrm{kg}$ of fenspiride (dose corresponding to the therapeutic dose for human patients with a speciesspecific conversion quotient), and 14 rats received $0.15 \mathrm{mg} / \mathrm{kg}$ of fenspiride. Control rats $(n=14)$ were injected with saline, and 10 rats served as an intact group. At the end of this procedure, the rats were euthanized with an overdose of sodium thiopental anesthetic.

To obtain samples for histological studies, rat lungs were expanded by intratracheal infusion of $10 \%$ formaldehyde solution. Tissue specimens were embedded in paraffin, microtome slices (5 to $7 \mu \mathrm{m}$ thick) stained with hematoxylin-eosin (H\&E) and examined at a 120-fold magnification using a binocular microscope MC 300 (S) (Micros, Austria).

Contractile activity of the bronchial smooth muscle was evaluated in vitro. Bronchial strips were taken as paired segments, 4 to $5 \mathrm{~mm}$ in width, and were isolated from bronchi of the 2nd-6th order. The bronchial strips 


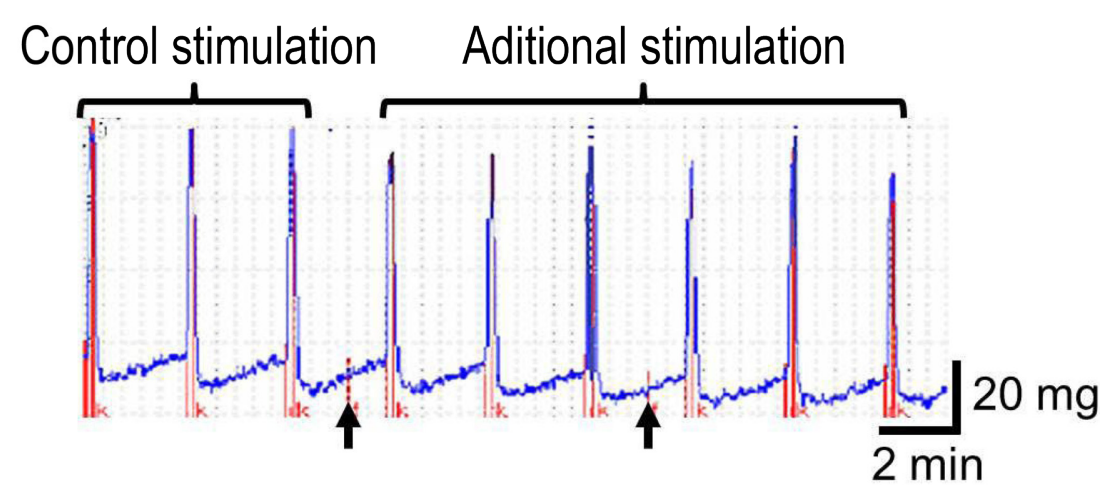

Fig. 1. Myogram. Contraction of a rat isolated bronchial preparation in response to field stimulation. Arrows indicate the application of fenspiride and novocaine into the organ bath.

were placed in a thermostatic flow bath (with a volume of $2.5 \mathrm{ml}$ ) perfused with Krebs-Henseleit solution with the following composition (mM): $\mathrm{NaCl} 118.0, \mathrm{KCl} 4.8, \mathrm{CaCl}_{2} 2.5, \mathrm{MgSO}_{4} 1.2, \mathrm{NaHCO}_{3} 11.9, \mathrm{KH}_{2} \mathrm{PO}_{4} 1.2$ and glucose 11.0 ( $\mathrm{pH}$ 7.4) using a peristaltic pump (Zampl, Poland) with a flow rate of $0.6 \mathrm{ml} / \mathrm{min}$. The solution was aerated with air from a microcompressor (MKM-7, Russia). To obtain a $\mathrm{pH}$ of 7.4, the sodium bicarbonate concentration was reduced to $11.9 \mathrm{mM}(7)$. The temperature was kept at $37-37.5^{\circ} \mathrm{C}$ with the aid of an ultrathermostat U10 (Medingen, GmbH, Germany). One side of each bronchial strip was fastened to the bottom of the bath using a tungsten needle, while the opposite side was attached to an electromechanical transducer (Russia). The initial force tension of the bronchial preparations was adjusted to $500 \mathrm{mg}$. Before starting the experiment, bronchial preparations were pre-incubated in the solution for $60 \mathrm{~min}$ to establish equilibrium of the resting tension. The changes in isometric contraction of the bronchial preparations (expressed as tension force in $\mathrm{mg}$ ) induced by electrical stimulation were evaluated. The bronchial muscle tension signals were fed into an analog-to-digital converter (L-CARD 14-140, Russia) and recorded on a computer (Fig. 1).

Using the electrical stimulator (ES-5, Russia), the bronchial preparations were subjected to electric field stimulation through platinum electrodes placed along the longitudinal walls of the bath. The stimulation parameters were as follows: $7 \mathrm{~Hz}, 0.5 \mathrm{~ms}$ (stimulation of preganglionic nerves) and $30 \mathrm{~Hz}, 2.0 \mathrm{~ms}$ (stimulation of smooth muscle cells). In all cases, the amplitude of the impulses was $20 \mathrm{~V}$ with a duration of $10 \mathrm{~s}$, at intervals of $2.5 \mathrm{~min}$ between impulses. For each bronchial preparation, contractile responses were measured after stimulation of both preganglionic nerves and smooth muscle in sequence. Each experimental set consisted of 9 excitation rounds. The average amplitude of the muscle contractions in response to three initial stimuli was considered to be the control (baseline) value. The mean amplitudes of the contractions after both 4-6, and 7-9 stimulations were referred to as a response to additional long-term stress, thus determining the contractile potential of the airway smooth muscle (Fig. 1) and were expressed as percentage ratios of the contraction amplitude of the control stimulation.

Additional experiments examined the pharmacological responses of bronchial preparations from intact rats. A flow bath containing the bronchial preparations (see above) was perfused with fenspiride $(1,10$ or 100 $\mu \mathrm{g} / \mathrm{ml})$ or novocain $(1 \mu \mathrm{g} / \mathrm{ml})$ for $8 \mathrm{~min}$. Bronchial preparations were stimulated 1,4 , and $7 \mathrm{~min}$ after adding the substance to the bath. Bronchial preparations underwent 30-min washings with saline between subsequent experimental series.

Statistical evaluation was performed using Microsoft Excel 7.0 software including calculations of mean values for maximal contraction amplitudes of bronchial smooth muscle preparations and the S.E.M. Compari- 


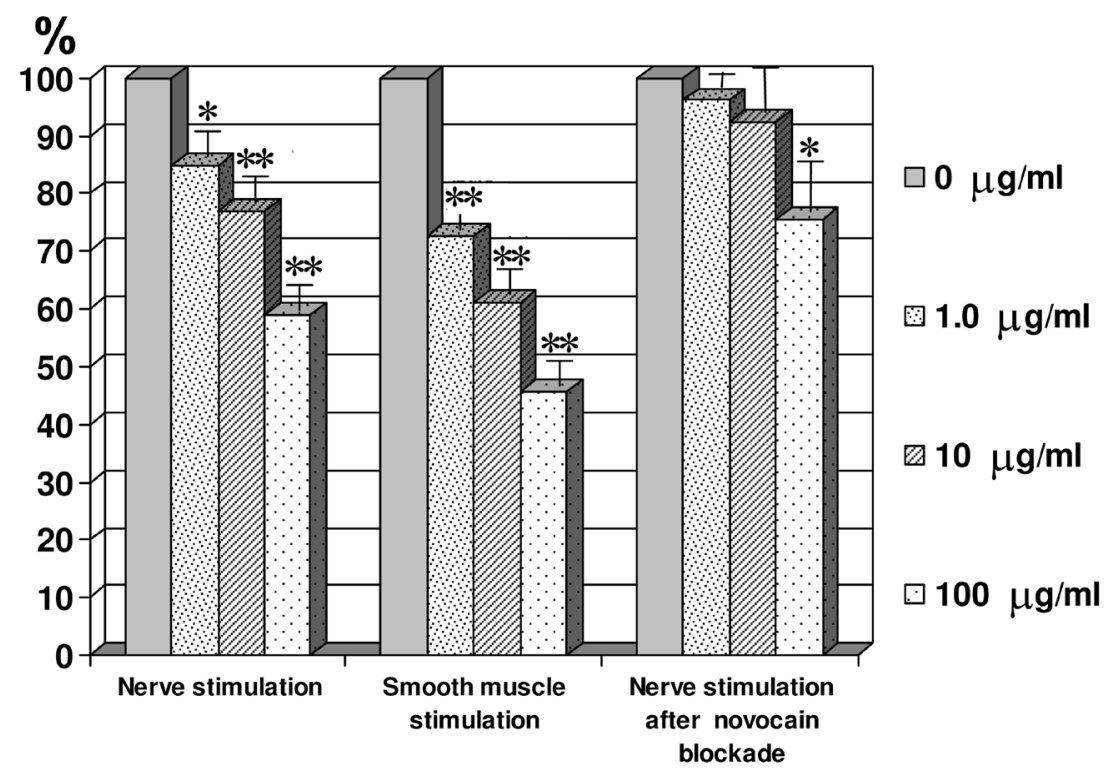

Fig. 2. Dose-dependence of ex vivo fenspiride effects on contractile activity of intact rat bronchial preparations. Y-axis - changes of bronchial contraction are expressed as percentage ratios of the initial contraction amplitude before the addition of fenspiride to the perfusate; $*$ and $* *$ - significant differences as compared with initial amplitude, $P<0.05$ and $P<0.01$ respectively.

son of mean values was performed using the Student's $t$-test, and pairwise comparison methods. A value of $P<0.05$ was considered to be significant.

\section{Results}

The ex vivo experiments with bronchial preparations from intact rats have shown that stimulation of preganglionic nerves caused smooth muscle contraction with a magnitude of $181.3 \pm 12.3 \mathrm{mg}$, while after smooth muscle stimulation, the magnitude was $266.5 \pm 15.0 \mathrm{mg}$. The addition of fenspiride $(1 \mu \mathrm{g} / \mathrm{ml})$ into the perfusion medium caused a significant decrease in the amplitude of the bronchial contraction elicited by electrical stimulation of both preganglionic nerves and smooth muscle by $15.0 \%$ and $27.4 \%(P<0.05)$ respectively. Increased concentrations of fenspiride caused a dose-dependent decrease of contractile response in both cases (Fig. 2).

When studying the effect of prednisolone on bronchi of intact and COPD model rats (8), we have shown that a reduction in the amplitude of the smooth muscle contractions was caused by the action of the drug on preganglionic nerve fibers. Novocaine or capsaicin blockade of the receptors prevents this relaxing effect. We assumed that prednisolone interacts with afferent nerve endings of C-fibers, inhibiting the release of tachykinins. Taking this fact into account, we have checked, whether the fenspiride effect is associated with the afferent nerve endings (receptors) of rat bronchi. Pretreatment with novocain $(1 \mu \mathrm{g} / \mathrm{ml})$ abolished the bronchial dilation caused by a low-dose of fenspiride ( 1 and $10 \mu \mathrm{g} / \mathrm{ml})$ in response to nerve stimulation, and significantly reduced the effect of a high-dose of fenspiride $(100 \mu \mathrm{g} / \mathrm{ml})$ - from $40.4 \pm 3.8 \%$ to $26.4 \pm 6.0 \%(P<0.05)$ (Fig. 2). It can be assumed that the dilatory effect of the low-dose of fenspiride is mediated by bronchial receptors, and that the effect of the high-dose of fenspiride may also be associated with bronchial smooth muscle, as its stimulation caused more marked dilatation than preganglionic nerve stimulation (Fig. 2).

A 60-day exposure of animals to $\mathrm{NO}_{2}$ was accompanied by the gradual development of COPD-like func- 
A

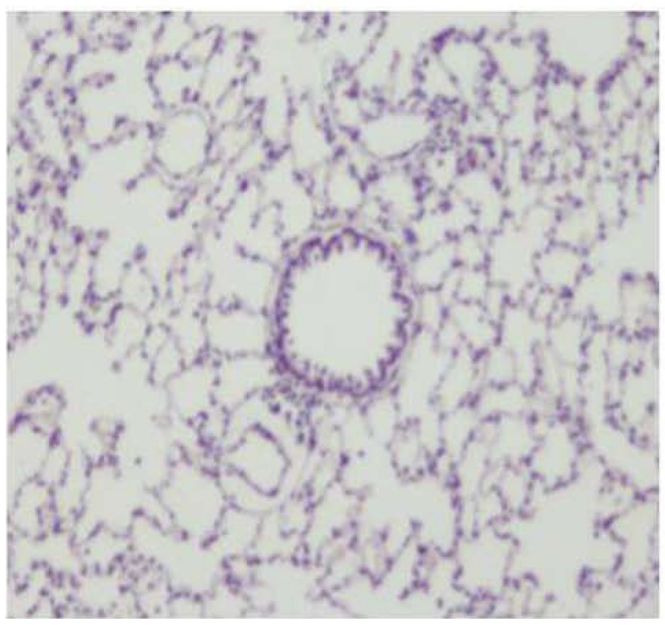

B

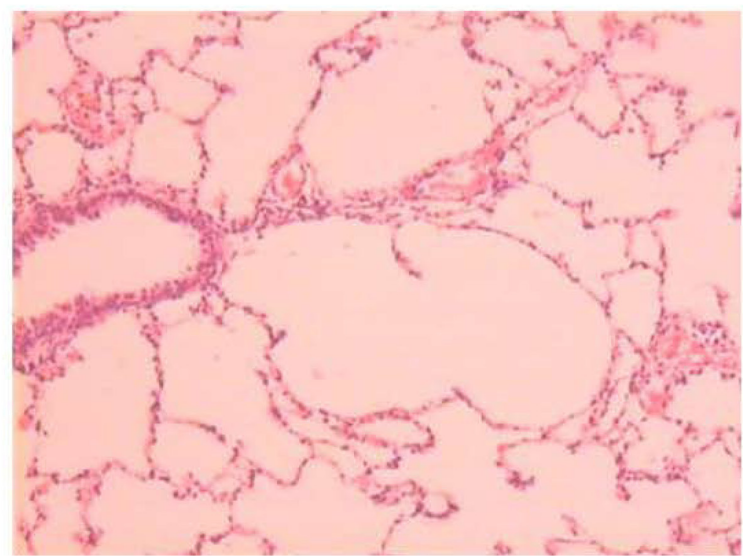

Fig. 3. A. Lung tissue of intact rat. $\mathrm{H} \& \mathrm{E}$ staining, $\times 120$. B. Lung tissue of rat after 60 -day exposure to $\mathrm{NO}_{2}$. Overdistension of alveoli, emphysema, thinning of interalveolar septa. H\&E staining, $\times 120$.

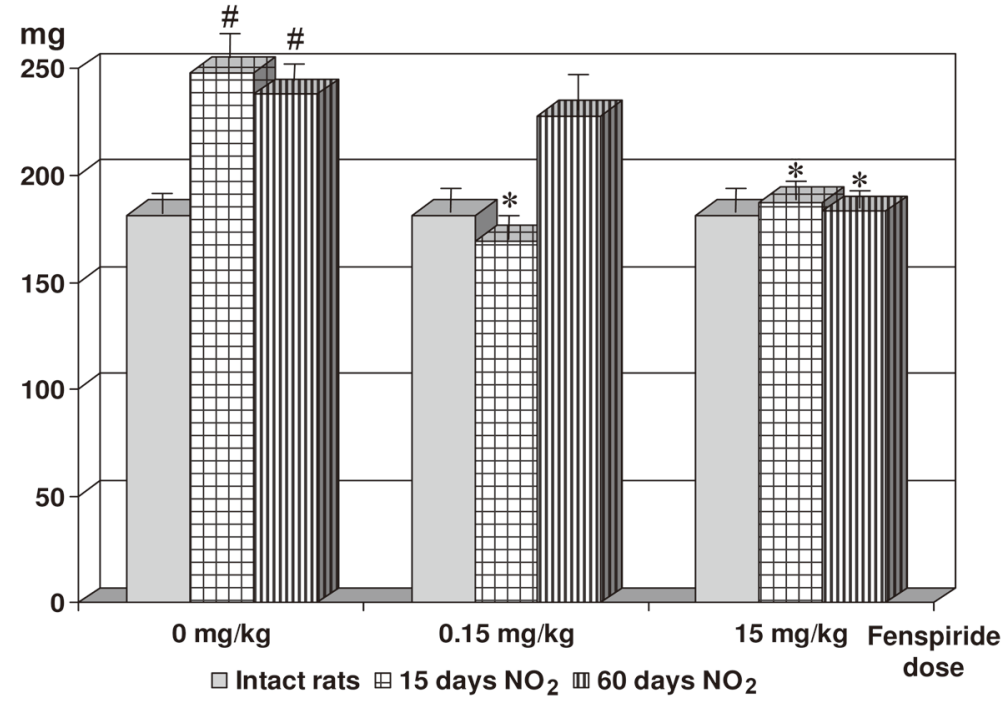

Fig. 4. Effects of in vivo fenspiride treatment on bronchial contractile activity caused by control stimulation of preganglionic nerves in COPD model rats. Y-axisbronchial contraction, $\mathrm{mg} ;{ }^{*}$, difference against fenspiride-free group is significant, $P<0.05$; \#, difference against intact rats is significant, $P<0.05$.

tional and morphological patterns, i.e., from immediate reaction to acute injury (at 15 day) followed by remodeling of pulmonary structures (60 days) (Fig. 3A, 3B) $(5,6)$. The bronchial smooth muscle of rats exposed to $\mathrm{NO}_{2}$ for 15-60 days enhanced its contractile activity in response to control nerve stimulation (Fig. 4; 0 $\mathrm{mg} / \mathrm{kg}$ ). The contractile response to control stimulation of the smooth muscle itself remained practically unchanged (Fig. $5 ; 0 \mathrm{mg} / \mathrm{kg}$ ). With additional nerve stimulation, an even greater increase in contraction amplitude (13-17\%) was observed (Fig. 6). The contractile reaction of additional stimulation of the smooth muscle was reduced by $20-22 \%(P<0.05)$ after 60 days of exposure to $\mathrm{NO}_{2}$ (Fig. 6).

We have shown earlier (9) that $\mathrm{NO}_{2}$ influences the afferent endings of capsaicin-sensitive C-fibers of bronchi, therefore we attempted to evaluate the treatment effect of the administration of fenspiride during the 


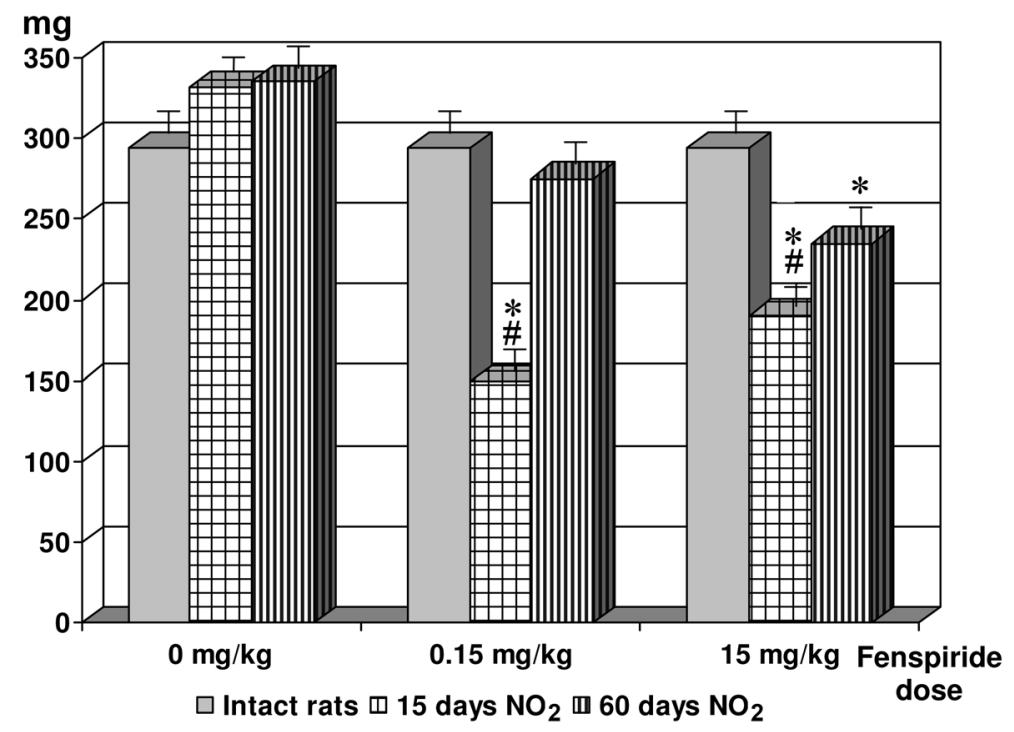

Fig. 5. Effects of in vivo fenspiride treatment on bronchial contractile activity caused by control stimulation of smooth muscle in COPD model rats. Y-axis-bronchial contraction, $\mathrm{mg} ;{ }^{*}$, difference against fenspiride-free group is significant, $P<0.05$; \#, difference against intact rats is significant, $P<0.05$.

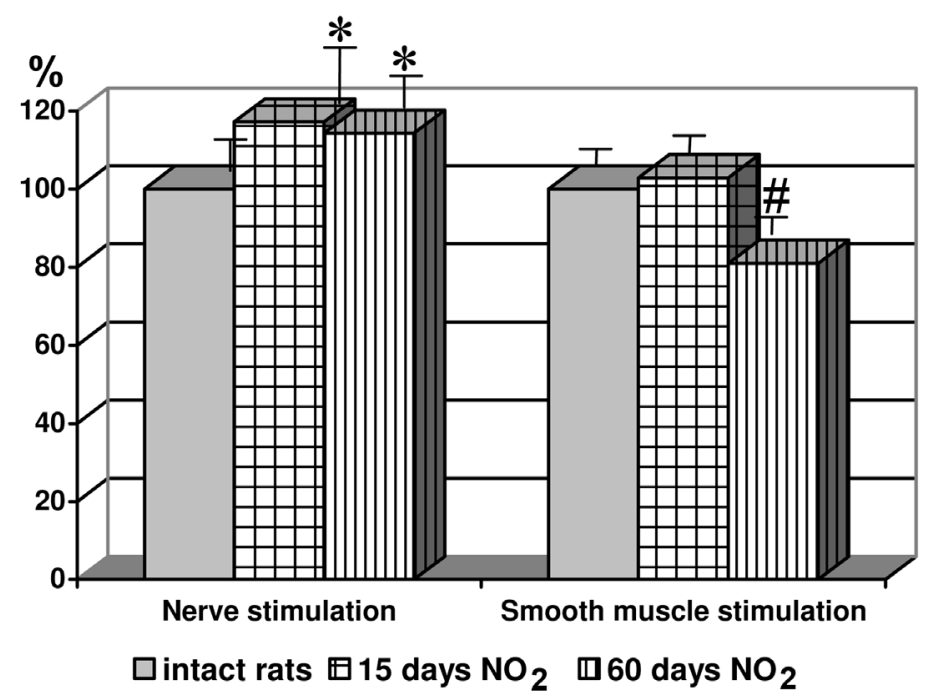

Fig. 6. Bronchial smooth muscle contractile responses to additional nerve or smooth muscle stimulation in rats with COPD. Y-axis - changes of bronchial contraction are expressed as percentage ratios of the contraction amplitude at control stimulation; * and ${ }^{*}$ - significant differences as compared with intact rats, $P<0.05$ and $P<0.01$ respectively.

development of COPD in the COPD-model rats. Taking into account that low fenspiride concentration interacts with bronchial receptors, and that high fenspiride concentration also affects smooth muscle (Fig. 2), we used two fenspiride doses: $15 \mathrm{mg}$ (high dose) and $0.15 \mathrm{mg}$ (low dose).

After 15-day $\mathrm{NO}_{2}$ exposure and daily administration of fenspiride (in both doses) the contractile responses of bronchial smooth muscle following control preganglionic nerve stimulation were lower than in the group of untreated rats and did not differ from the responses of bronchial preparations of intact rats (Fig. 4). After 

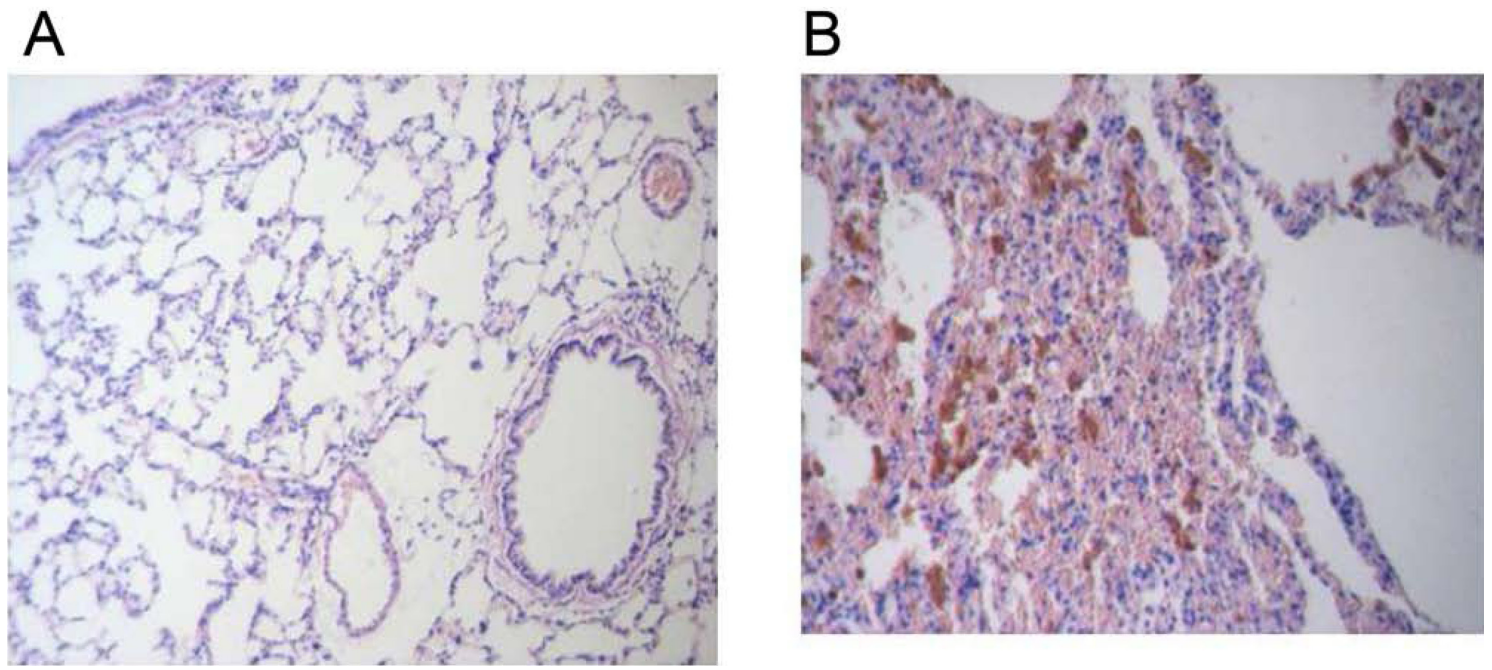

Fig. 7. A. Lung tissue of rat after 60 -day exposure to $\mathrm{NO}_{2}$ and treatment with fenspiride $(0.15 \mathrm{mg} / \mathrm{kg})$. Lung tissue is virtually unchanged with a slight expansion of alveoli. H\&E staining, $\times 120$. B. Lung tissue of rat after 60-day exposure to $\mathrm{NO}_{2}$ and treatment with fenspiride $(15.0 \mathrm{mg} / \mathrm{kg})$. Oedema, hemorrhage, large number of hemosiderophages. H\&E staining, $\times 120$.

control smooth muscle stimulation, the contraction amplitude of bronchial preparations from fenspiride-treated rats was less than in non-treated and intact animals (Fig. 5). Moreover, responses of isolated bronchi to additional nerve stimulation, regardless of in vivo fenspiride doses, were lower $(89.8 \pm 4.0 \%$ for $0.15 \mathrm{mg} / \mathrm{kg}$ and $107.7 \pm 2.4 \%$ for $15 \mathrm{mg} / \mathrm{kg})$ than in untreated rats $(117.6 \pm 5.4 \%, P<0.05)$, and these values did not differ from those in intact rats. Responses of isolated bronchi to additional smooth muscle stimulation in rats treated with both low and high fenspiride doses were lower $(88.8 \pm 3.8 \%$ and $88.2 \pm 4.1 \%$ respectively) than bronchial responses of untreated rats $(102.9 \pm 2.6 \%, P<0.05)$.

After 60-days of exposure to $\mathrm{NO}_{2}$, only high-dose fenspiride treatment caused a decreased contractile bronchial response following control preganglionic nerve stimulation (Fig. 4) and, more markedly after smooth muscle stimulation (Fig. 5). An additional nerve stimulation enhanced smooth muscle contraction of bronchi isolated from untreated rats, whereas after fenspiride treatment (at either dose) bronchial contractile activity did not increase. Following additional smooth muscle stimulation, the amplitudes of bronchial contraction in fenspiride-treated rats (in both doses) were lower $(70.2 \pm 3.3 \%, P<0.01)$, than in untreated group $(116.0 \pm 6.7 \%)$ or intact rats $(101.2 \pm 3.1 \%)$.

Lung tissue in rats treated with low doses of fenspiride exhibited normal air density. Expanded alveoli and moderate cellular infiltration were rarely detectable, with an absence of the marked structural lesions typical of untreated rats with COPD (emphysema, fibrosis foci), as seen in Fig. 7A. Thus, a dual mode of fenspiride interaction with C-fiber receptors may be presumed. Firstly a facilitation of its bronchodilator effect and secondly by preventing initiation of neurogenic inflammation. The bronchodilator effect of fenspiride at a therapeutic dose was confirmed histologically with the appearance of lumenal enlargement of the bronchi, along with a reduced number of goblet cells. Serous fluid and partially hemolysed red blood cells were detected in the alveolar spaces (hemorrhage of different terms), as seen in Fig. 7B. Inflammatory changes were manifested as exudation and lymphocyte-macrophage proliferation in the lung interstitial tissue. Morphological changes were not specific to COPD rats and were most likely due to the toxic effect of $\mathrm{NO}_{2}$. 


\section{Discussion}

This study has shown that the mechanisms of fenspiride action on bronchial smooth muscle depend on its dose. At a low dose of fenspiride, a dilatory effect was observed in the acute COPD stage (15-day $\mathrm{NO}_{2}$ exposure) which seems to be mediated by interaction with nerve endings of capsaicin-sensitive C-fibers in the bronchi. The lack of such a bronchodilator effect at lower fenspiride dose during overt COPD (60-day $\mathrm{NO}_{2}$ exposure) may be explained by a previously described phenomenon of C-fiber inactivation that occurs during prolonged exposure to nitrogen dioxide (9). Fenspiride, if applied at a therapeutic dose (15 mg/kg) caused a more pronounced decrease in the amplitude of bronchial smooth muscle contraction upon direct stimulation of the muscle, than with preganglionic nerve stimulation. It can be assumed that the bronchodilator effect of fenspiride in this case may be mediated not only via stimulation of afferent nerves, but also due to its direct relaxing effect upon smooth muscle cells. Girard et al. (10) have found that fenspiride at low concentrations $\left(10^{-6}-10^{-4} \mathrm{M}\right)$ is able to reduce the release of neuropeptides including tachykinins from sensory presynaptic endings. At higher concentrations $\left(>10^{-4} \mathrm{M}\right)$ fenspiride exerts its postsynaptic action directly on bronchial smooth muscle cells.

The data obtained suggests that fenspiride may be a promising tool for COPD medication, as well as its long-term application within novel treatment protocols in order to prevent this disorder. Our observations on the COPD-preventing efficiency of fenspiride at sub-therapeutic doses are of particular importance. This fact allows us to recommend a long-term use of fenspiride in patients from the at-risk group for COPD, e.g., for persons exposed to aggressive airborn toxins (pollutants, occupational hazards, cigarette smoke, etc.).

\section{References}

1. Barnes PJ. How corticosteroids control inflammation: Quintiles prize lecture. Br J Pharmacol. 2006; 148 (3): 245-54.

2. Shmelev EI, Kunicina YL. Comparison of fenspiride with beclomethasone as adjunctive anti-inflammatory treatment in patients with chronic obstructive pulmonary disease. Clin Drug Invest. 2006; 26 (3): 151-9.

3. Khawaja AM, Liu YC, Rogers DF. Effect of fenspiride, a non-steroidal anti-inflammatory agent, on neurogenic mucus secretion in ferret trachea in vitro. Pulm Pharmocol Ther. 1999; 12 (6): 363-8.

4. van Zutphen LFM, Baumans V, Beynen AC, editors. Principles of Laboratory Animal Science. rev ed. Amsterdam: Elsevier; 2001. 428p.

5. Dvorakovskaya IV, Lebedeva ES, Kuzubova NA, Danilov LN. Model of staged development chronic obstructive pulmonary disease (COPD) in rats. Amsterdam: ERS Ann Cong; 2011. 3899p.

6. Lebedeva ES, Kuzubova NA, Danilov LN, Titova ON, Dvorakovskaya IV, Preobrazhenskaya TN, Platonova IS. Experimental Modelling of Chronic Obstructive Pulmonary Disease. Bull Exper Biol Med. 2012; 152 (5): 659-63. doi: 10.1007/s10517-012-1601-3.

7. Blattner R, Classen HG, Dehnert H, Doring HJ. Experiments on isolated smooth muscle preparations. Freiburg: Hugo Sachs Elektronik KG; 1978. 185 p. English edition prepared by Barnden IM, Colson R. 1980.

8. [Fedin A N, Kuzubova N A, Danilov LN, Lebedeva ES, Postnikova TYu, Krivchenko A I. Broncholytic effect of prednisolon in the rats inhaled with nitrogen dioxide. Russ J Physiol. 2010; 96 (3): 293-300].

9. [Fedin AN, Postnikova TYu, Kuzubova NA, Danilov LN, Lebedeva ES. Alteration of trachea and bronchi smooth muscles constriction under long inhalation of dioxide nitrogen by rats. Russ J Physiol. 2007; 
93 (10): 1163-70].

10. Girard V, Naline E, Crambes O, Malbezin M, Malmström RE, Lundberg JM, Advenier C. Pre- and postjunctional inhibitory effects of fenspiride on quinea-pig bronchi. Eur Resp J. 1997; 10 (5): 1015-20. 